\title{
ETHOS NA PRÁTICA POLÍTICA: UMA ANÁLISE COMPARATIVA EM CONTEXTOS LUSO-BRASILEIROS
}

\author{
ETHOS WITHIN THE POLITICAL PRACTICE: A COMPARATIVE \\ ANALYSIS IN LUSO-BRAZILIAN CONTEXTS
}

\author{
Sara Pita ${ }^{141}$ \\ Rosalice Pinto ${ }^{142}$
}

RESUMO: O objetivo deste artigo é, num primeiro momento, identificar os ethè construídos por chefes de governo portugueses e brasileiros, demonstrando o seu caráter simbiótico e, em seguida, estabelecer uma análise comparativa dos ethè políticos construídos. De forma a atingir o objetivo pretendido, sâo selecionados alguns discursos políticos de final de ano desses estadistas, nomeadamente os pronunciados em 2011 e 2012. A partir do levantamento de algumas marcas de responsabilidade enunciativa (Adam, 2008) e usando como suporte a tipologia sobre o ethos de Charaudeau (2013), identificar-se-âo as imagens mobilizadas pelos enunciadores nos discursos por eles produzidos, visando a estabelecer uma tipologia inicial dos ethè centrada em uma base linguística. Resultados preliminares permitem identificar dois ethè comuns (competente e agente) e indiciam que as categorias linguísticas selecionadas têm seu grau de relevância tanto para a caracterizaçấo dos ethè, quanto para o estabelecimento de uma análise contrastiva dos elementos linguísticos identificados.

Palavras-chave: Ethos; ethos simbiótico; discurso político; categorias linguísticas.

ABSTRACT: The aim of this paper is to, first of all, identify the ethè built by the Portuguese and Brazilian heads of government, so as to show their symbiotic character and, secondly, to establish a comparative analysis of the constructed political ethè.In:order to reach the aimed goal, some end-of-the-year political speeches are chosen, from 2011 and 2012. From some enunciative responsibility marks (Adam, 2008) and using as a support the typology for the ethos pointed out by Charaudeau (2013), we shall identify the images which were constructed by the enunciators of the political speeches. By doing this, we will seek to establish an initial ethè typology focused on a linguistic

141 Sara Pita: Faculdade de Ciências Sociais e Humanas - Centro de Linguística da Universidade Nova de Lisboa, Lisboa, Portugal, Doutoranda em Linguística, saratopete@ua.pt

142 Rosalice Pinto: Faculdade de Ciências Sociais e Humanas - Centro de Linguística da Universidade Nova de Lisboa, Lisboa, Portugal, Prof. Doutora em Linguística - Investigadora do CLUNL e do CEDIS, rpinto@ fcsh.unl.pt 
basis. Preliminary results show the existence of two common ethè (competent and agent) and show that the selected linguistic categories are important both for the specification of the ethè and for a contrastive analysis of the identified linguistic elements.

Keywords: Ethos; symbiotic ethos; political discourse; linguistic categories

\section{CONSIDERAÇÕES INICIAIS}

A noçăo de ethos (imagens do enunciador), integrando uma tríade discursiva, constituída ainda pelo pathos (a exploraçăo das emoçōes do auditório) e o logos (a apresentaçăo da prova da verdade dos seus argumentos), remonta à antiguidade clássica, particularmente aos estudos retóricos de Aristóteles (2005). Nos estudos contemporâneos, sâo vários os teóricos que retomaram a questâo. Barthes (1970) define o ethos como os traços de caráter que o orador deve mostrar ao destinatário, através do discurso, ${ }^{143}$ para causar boa impressăo e para o convencer. Maingueneau (2006) postula que o orador deve reproduzir o ethos típico do auditório para promover a adesăo deste e Amossy (2005) acrescenta que necessita de recorrer também ao seu estilo e saberes para transmitir uma sensaçáo de realidade ao ethos. Charaudeau (2013) entende que a construçấo do ethos depende das representaçôes sociais, morais e ideológicas do destinatário. Kerbrat-Orecchioni (1998) considera que em qualquer processo comunicativo os "interactantes" influenciam-se reciprocamente e que o sucesso do discurso depende do respeito pelos comportamentos e pelas crenças partilhadas pelo ethos coletivo.

Face a este contexto, esta contribuiçấo, que corresponde a um recorte da tese de doutoramento em curso, tem como objetivo identificar alguns ethè políticos construídos em discursos de final de ano de chefes de governo do Brasil e de Portugal, em 2011 e 2012, a partir do levantamento de algumas estratégias linguísticas por eles utilizadas. Neste sentido, identificar-se-âo as imagens mobilizadas pelo enunciador nos discursos, usando como suporte teórico a tipologia pragmático-discursiva de Charaudeau (2013). De seguida, analisar-se-âo linguisticamente os ethè, em particular os de competente e de agente, focalizando no estudo de algumas marcas de responsabilidade enunciativa (Adam, 2008) e de algumas formas de tratamento em Português europeu e alguns tempos verbais utilizados - (DUARTE, 2010; CARREIRA, 2001). Em funçăo dos resultados obtidos, algumas pistas podem ser evidenciadas sobre a materialidade linguística dos ethè e sobre os elementos linguísticos comuns/distintos nos textos produzidos nos dois contextos lusófonos.

\section{AS DIFERENTES ABORDAGENS AO CONCEITO DE ETHOS}

Vale salientar que o ethos sempre foi considerado um elemento fundamental para o sucesso de um discurso, pois diz respeito aos traços de caráter que o orador

143 O termo de discurso corresponde neste artigo a determinada atividade prática (política, jurídica, jornalística, por exemplo), empiricamente e linguisticamente expressa por textos. A semiotizaçăo destes será influenciada pelas práticas sociais e históricas em que estiverem inseridos. 
demonstra, por meio do discurso, ao seu destinatário para causar boa impressấo e para o convencer (BARTHES, 2009). Este mesmo autor (corroborando o pensamento aristotélico) defendia que o ethos năo tinha de corresponder forçosamente ao caráter autêntico do orador, pois o que importava era a imagem transmitida pelo discurso e năo o seu comportamento na interaçăo real. Năo obstante, a forma como a mensagem de um sujeito é percebida e recebida por outro depende, em certa medida, dos traços do orador e dos papéis que este desempenha, de acordo com a opiniâo de alguns retóricos, de entre eles Perelman (1977).

Nos estudos estritamente linguísticos ou textuais-discursivos, foram vários os autores que recuperaram a noçăo. Ducrot incorporou, na sua Teoria Polifónica da Enunciaçâo, o termo, associando-o ao Locutor (L). Para este autor, o enunciado apresenta vários sujeitos, aos quais atribui a autoria da enunciaçăo: o "locutor enquanto tal" (L), responsável pela enunciaçăo, e o "locutor enquanto ser do mundo" ( ), pessoa real que deu origem ao enunciado. De modo a evidenciar a diferença entre estas duas entidades, Ducrot apresentou vários argumentos. Em primeiro lugar, referiu que L exprime os seus sentimentos, situados na própria enunciaçăo, ao passo que apresenta os seus sentimentos reais, logo externos à enunciaçăo. Em segundo lugar, recorreu ao conceito de ethos, o qual liga a L, entidade discursiva à qual atribui certas características que podem tornar a sua enunciaçâo credível ou desagradável.

Dans ma terminologie, je dirai que l»éthos est attaché à L, le locuteur en tant que tel: c»est en tant qu»il est source de l»énonciation qu»il se voit affublé de certains caractères qui, para contrecoup, rendent cette énonciation acceptable ou rebutante (DUCROT, 1984, p. 201).

Assim sendo, para Ducrot, o ethos é tudo o que se relaciona com o Locutor, o ser falante que produz a enunciaçăo, nomeadamente a escolha dos argumentos, das palavras e da colocaçấo da voz. A forma como se apresenta ao mundo através da enunciaçâo tornam o seu caráter aceitável ou desagradável aos olhos do destinatário.

Mas, para além destes traços individuais, o orador deve também mostrar pelo seu discurso "o ethos característico do auditório, para dar-lhe a impressâo de que é um dos seus que se dirige a ele" (Maingueneau, 2006, p. 55). Ou ainda, segundo Charaudeau, a construçăo do ethos implica a consideraçăo de representaçôes sociais, morais e ideológicas do auditório, os seus referentes ideais ou os "imaginários sociodiscursivos".

Toda construçâo do ethos se faz em uma relaçâo triangular entre si, o outro e um terceiro ausente, portador de uma imagem ideal de referência: o si procura endossar essa imagem ideal; o outro se deixa levar por um comportamento de adesáo à pessoa que a ele se dirige por intermédio dessa mesma imagem ideal de referência. (CHARAUDEAU, 2013, p. 137)

O ethos foi, igualmente, abordado numa perspetiva interacionista, nomeadamente por Plantin e Kerbrat-Orecchioni. Para estes autores, o ethos não é uma estratégia persuasiva usada para convencer o auditório das qualidades do orador, como na visão aristotélica, é sim uma apresentação de si, reveladora dos matizes da sua personalidade (KERBRAT-ORECCHIONI, 2002, p. 184). Por este motivo, são recuperados os conceitos 
de imagem de si e de face ${ }^{144}$ de Goffman (1974), que inserem o ethos na problemática da "construçâo interativa das identidades" (KERBRAT-ORECCHIONI, 2002, p. 188).

Embora Bronckart nâo utilize a noçâo de ethos, considera-se que as suas posiçôes sobre os tipos de discurso e sobre o envolvimento enunciativo constituem aportes importantes para a análise a realizar durante este trabalho de investigaçáo.

A partir deste enquadramento teórico, as investigadoras consideram que o ethos corresponde às imagens que o Locutor constrói durante as suas intervençóes por meio da materialidade linguística que mobiliza, imagens essas que podem ser representativas da sua personalidade, das expectativas que entende que o auditório tem e das qualidades que este considera mais importantes. Deste modo, o ethos é simbiótico, porque se refere ao processo de coconstrução de imagens de si, no e pelo discurso. Por outras palavras, o Locutor constrói uma imagem nâo só mediante a sua personalidade, as suas crenças, os seus valores e objetivos (representaçōes individuais), mas também em funçăo do seu auditório, no qual se integra como cidadâo, e do seu imaginário (representaçóes coletivas), daí que se considera que o ethos será uma simbiose entre o individual e o coletivo. Uma vez construída a imagem, o Locutor solicita a atribuiçâo de um sentido ao auditório e, dependendo da reaçăo deste, poderá haver necessidade de uma reformulaçăo. A figura 1, apresentada em seguida, pretende ilustrar o processo de construçăo do ethos simbiótico.

Figura 1 - Ethos simbiótico

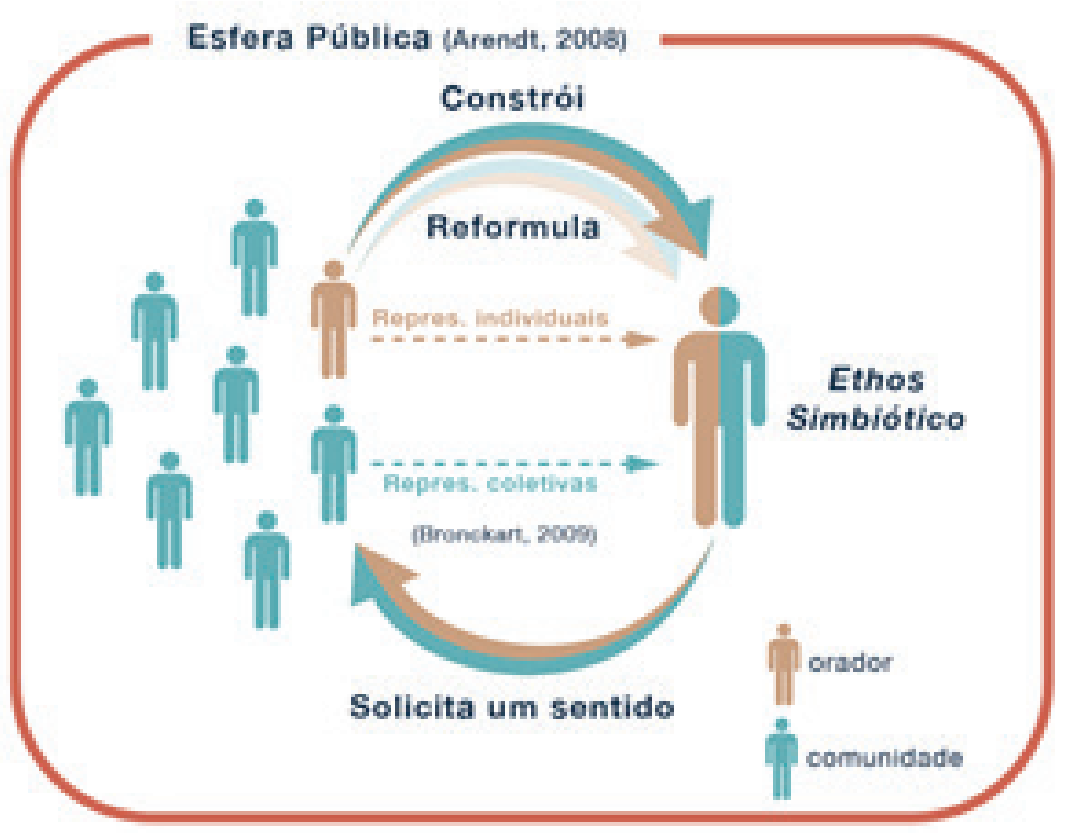

Fonte: As autoras

144 Goffman (1974) define este termo como o valor social positivo que um indivíduo reclama para si durante uma troca comunicativa. Sendo assim, a face corresponde à imagem de si construída em funçáo de valores aprovados por uma dada sociedade. 


\section{ASPETOS METODOLÓGICOS}

\section{Corpus de análise}

Quanto ao corpus, a decisâo de centrar o estudo neste grupo de textos ${ }^{145}$ deveu-se à necessidade de uniformizaçâo. Para além da prática política ser bastante prolífera ao nível comunicacional, também as diferenças referentes aos sistemas políticos de Portugal e do Brasil (república democrática semipresidencialista e república federal presidencialista, respetivamente) dificultaram a seleçăo dos textos. A soluçáo encontrada para garantir a equidade passou pela recolha de textos produzidos no final do ano civil pelos Chefes de Governo de ambos os países, o que em Portugal corresponde ao Primeiro-Ministro e no Brasil, ao Presidente da República. Devido ao período temporal definido para este estudo, observaram-se mudanças em relaçâo aos representantes políticos, pelo que do corpus constam texto pronunciados por José Sócrates e Pedro Passos Coelho, no contexto português, e Lula da Silva e Dilma Rousseff, no contexto brasileiro.

Os textos selecionados têm como objetivo apresentar um relatório sobre a performance passada e futura do governo e, por terem como destinatário todos os cidadáos da naçấo, săo transmitidos em direto pelos meios de comunicaçăo televisivos e divulgados na íntegra ou de forma parcial pela imprensa escrita a posteriori. Estes textos sâo também disponibilizados, em versâo integral, nos sítios oficiais dos respetivos governo, locais de onde se retiraram os exemplares usados durante esta investigaçáo. ${ }^{146}$

\section{MODELO GERAL DE ANÁLISE LINGUÍSTICO-TEXTUAL}

A análise conduzida neste artigo é de cariz misto, embora a observaçâo qualitativa seja a mais relevante. No entanto, considera-se que a contabilizaçâo de alguns dados importantes para a construçăo dos ethè, nomeadamente a frequência vocabular ou a distribuiçăo dos índices de pessoas e dos tempos verbais, pode ser relevante para a formulaçăo de generalizaçôes. Os dados de ordem quantitativa foram obtidos com o apoio do software Concordance e trabalhados no Excel pela investigadora.

Para a análise qualitativa foram definidos diversos elementos linguístico-textuais que seriam sujeitos a observaçấo, importados de diversos autores, de entre os quais os índices de pessoa (formas pronominais pessoais e possessivas, bem como morfemas de pessoa usados nas formas verbais), os tempos verbais, os indicadores espaciais e temporais, os organizadores de discurso, os conetores e marcadores, os atos de discurso, as modalidades (BRONCKART, 1996; ADAM, 2008), as escolhas lexicais (KerbratOrecchioni, 2002), as formas de tratamento (CARREIRA, 2001) e os esquemas argumentativos (WALTON et al., 2008). Em algumas situaçōes verificou-se inclusivamente que alguns autores faziam referência às mesmas categorias de análise, o que veio

145 Faz-se a ressalva que para este trabalho as "mensagens de final de ano" ainda constituem um agrupamento de textos, náo se tratando de um gênero textual atestado. No entanto, na tese de doutoramento em andamento, estarăo sendo apresentadas as razóes que podem vir a caracterizar a mensagem de final de ano como um gênero textual. Importa ainda salientar que se adotou a nomenclatura "género de texto" ou "género textual" por se considerar que esta expressáo indica com mais clareza a relaçâo entre prática discursiva, situaçáo comunicativa e texto, estando este permeável às mudanças culturais, sociais e históricas observáveis nas atividades da vida humana.

146 Disponíveis em: <http://www.portugal.gov.pt/>; ‘http://www2.planalto.gov.br>. 
corroborar a importância de considerar estes elementos no momento da observaçăo.

Um elemento de análise relevante inclusive para as análises apresentadas neste artigo diz respeito às formas de tratamento e a alguns vocábulos específicos por determinarem o tipo de relaçăo vivida entre os intervenientes de uma interaçăo (KERBRAT-ORECCHIONI, 2002). Em língua portuguesa, em especial na variante europeia, há uma distinçâo clara entre o "tu" e "você", denotando o primeiro uma relaçâo de intimidade e o segundo uma relaçăo de distância. O pronome "você", em Portugal, é inclusivamente visto como a forma polida, delicada e respeitosa de se dirigir ao outro, marcando as fronteiras do território individual. Já no Brasil, o "você" é o pronome mais utilizado nas interaçóes familiares quotidianas sendo privilegiado em relaçăo ao "tu". De entre as formas de tratamento, a autora inclui as seguintes unidades linguísticas: antropónimos ou nomes pessoais, termos de parentesco, apelativos (como por exemplo "Senhor(a)"), termos que definem a natureza da relaçăo entre locutor e alocutário, termos afetuosos ou injuriosos.

Este artigo, que corresponde a um recorte da tese de doutoramento em curso, por limitaçôes espaciais, restringir-se-á a pontuar dois ethè comuns e distintos presentes nos discursos políticos luso-brasileiros, a partir da materialidade linguística dos mesmos.

\section{RESULTADOS DA ANÁLISE LINGUÍSTICO-TEXTUAL DE EXCERTOS DAS MENSAGENS DE FINAL DE ANO}

A análise de alguns excertos dos textos permitiu observar a existência de dois ethè comuns: competente e agente em potência, mas com algumas diferenças atestadas ao nível da materialidade linguística. O primeiro diz respeito à demonstraçaáo da competência do executivo e o segundo à exposiçáo de projetos a implementar no futuro. De ressalvar que neste último tipo de ethos não existe qualquer vínculo formal entre a promessa e a sua execuçăo, razăo pela qual se optou por usar a expressăo "em potência" para salientar o caráter intencional desta figura.

O ethos competente foi construído, na maioria dos textos, com recurso às mesmas marcas linguísticas, mas detetaram-se algumas diferenças que podem influenciar a forma como a imagem é percebida pelo público.

Relativamente às semelhanças, identificou-se o uso do sujeito subentendido nós institucional ou do sujeito expresso o governo, implicando a $1 .^{a}$ pessoa do plural ou a 3. ${ }^{a}$ pessoa do singular das formas verbais, respetivamente; o recurso aos Pretéritos Perfeitos Simples e Composto do Indicativo de verbos de açâo; e a indicaçăo das medidas implementadas, normalmente como complemento direto do verbo.

PT2013: Entrámos em mercados em que Portugal nunca tinha entrado antes e temos hoje excedentes comerciais e financeiros sobre o exterior, algo que Portugal nâo conhecia há muitas décadas. Começámos a vergar a dívida externa e pública que tanto tem assombrado a nossa vida coletiva.

BR2013: Continuamos nossa luta incansável pela construçâo de um grande futuro para o Brasil, viabilizando a exploraçâo do pré-sal e garantindo a destinaçâo de seus fabulosos recursos para a educaçăo e a saúde. 
Em relaçăo às diferenças, observa-se, por exemplo, o uso frequente da perífrase com valor em curso ("estar + gerúndio") nas mensagens brasileiras, por oposiçăo à ocorrência residual observada nas mensagens portuguesas, o que pode levantar a dúvida sobre a inoperância do governo dado que apresenta menos resultados. Outra diferença diz respeito ao uso de indicadores temporais nos textos brasileiros, expondo claramente o período em que determinada açáo ocorreu.

Após o confronto entre as duas variantes da língua verificou-se que a materialidade linguística do ethos agente em potência é semelhante, embora nos textos portugueses se encontrem várias oraçóes finais para explicitar o propósito de algumas medidas. Portanto, ao nível da materialidade linguística mobilizada para a construçâo do ethos agente em potência foram identificados os seguintes elementos: sujeito subentendido nós institucional ou sujeito expresso o governo; 1 . $^{\mathrm{a}}$ pessoa do plural ou 3. ${ }^{\mathrm{a}}$ pessoa do singular das formas verbais; presente e futuro imperfeito do Indicativo; perífrase de futuro, volitiva e de necessidade; verbos de açâo; indicadores temporais.

PT2013: Precisaremos de todos os instrumentos que mobilizámos para concluir sem perturbaçóes o Programa. E precisaremos de os usar bem, com inteligência e determinaçăo.

Na PT2012 surgem alguns ethè específicos, em particular o de comandante e o de patriota. No primeiro caso, o Locutor assume uma posiçăo individual, marcada pela 1. a pessoa do singular dos pronomes e/ou das formas verbais, ou uma posiçâo coletiva, em representaçâo dos cidadâos, marcada pela 1. ${ }^{a}$ pessoa do plural. Estes momentos săo utilizados pelo Locutor para motivar e conduzir o auditório, utilizando para tal expressóes de cariz militar (assinaladas a negrito no excerto), ou para fazer referência aos militares que estariam sob a sua "alçada" (convém referir que o Primeiro Ministro năo detém a funçấo de Comandante Supremo das Forças Armadas).

PT2012: Ainda nâo podemos declarar vitória sobre a crise, mas estamos hoje muito mais perto de o conseguir. E uma condiçăo essencial para sermos vitoriosos sobre a dívida e sobre o desemprego é acreditarmos em nós próprios.

A imagem de comandante foi referida por Charaudeau, mas nâo deve ser aqui entendida no mesmo sentido de que fala este autor. No entender das investigadoras, refere-se ao dirigente ou líder de uma força militar, e nâo ao senhor da guerra, agressivo e autoritário postulado por Charaudeau (2013, p. 159). Normalmente, associa-se uma certa rigidez às funçōes militares, em virtude de seguirem um código de conduta rígido. Assim, embora o Locutor pretenda demonstrar competências de liderança, trata-se de um ethos diferente do de líder, pois aqui năo se admitem fugas ao padrâo.

O ethos patriota, no qual se expressava o sentido de uniăo do país, foi construído com recurso à $1 .^{a}$ pessoa do singular ou do plural, neste caso em representaçâo do executivo governativo. Os verbos encontravam-se sempre no Presente do Indicativo, pois o Locutor pretendia demonstrar a sua conjugaçâo com o momento da enunciaçấo, revelando assim que se tratava de um sentimento atual. Para mostrar o patriotismo, foram selecionados vocábulos específicos, nomeadamente "povo", "concidadāos", "emigrantes", "comunidades portuguesas" ou "todos os portugueses". A mençâo a todos os portugueses, e năo apenas aos que se encontram em território nacional, promove a integraçâo de todos os cidadâos, transmitindo uma ideia de pertença a uma Pátria. 
PT2012: Como sempre acontece, esta quadra natalícia será um momento especial para recordarmos aqueles que estâo mais longe, ou aqueles que se afastaram de nós no último ano. Devemos lembrar as comunidades portuguesas e todos os emigrantes no estrangeiro, ou os nossos militares em missóes noutras regiōes do planeta.

\section{DISCUSSÃO DOS RESULTADOS}

Resultados preliminares apontam que o ethos simbiótico é uma característica do ethos construído nestes discursos em que o ator político deve construir a sua imagem discursivamente, em funçāo do momento em que o discurso é proferido (final de ano), expectativas do público a quem se dirige, contextos espaciais e culturais diversos. Enfim, esta simbiose que abrange imagens de líder, de competência, de comando, de patriotismo é construída em funçâo de características linguísticas diversas, estabelecendo-se divergências e convergências entre os dois contextos lusófonos. Dois tipos de ethè são específicos do contexto português: o de comando e o de patriotismo. Tais especificidades podem talvez ser explicadas por questôes culturais, histórico-sociais de Portugal. É neste sentido que a abordagem de uma linguística de gêneros, como salienta Rastier (2001, p. 231), pode vir a ser relevante para o estudo desse ethos simbiótico. Parte-se assim do princípio que o texto, forçosamente inserido em um gênero, só poderá ser analisado em funçăo de questôes contextuais diversas que lhe săo "intrinsecamente constitutivas".

Evidentemente, com este artigo, algumas pistas foram apontadas, mas seria conveniente proceder a outras análises para aprofundar este tema. 


\section{REFERÊNCIAS}

ADAM, J.-M. A linguística textual: introduçăo à análise textual dos discursos. Săo Paulo: Cortez, 2008.

AMOSSY, R. Imagens de si no discurso: a construçâo do ethos. Săo Paulo: Contexto, 2005. ARENDT, H. The promise of politics. Berlim: Schocken Books, 2007.

ARISTÓTELES. Retórica. Lisboa: Imprensa Nacional Casa da Moeda, 2005.

BARTHES, R. L"ancienne rhétorique. Communications 16, pp. 171-223, 1970.

Bronckart, J.-P. Activité langagière, textes et discours. Pour un interactionisme sociodiscursif. Lausanne: Delachaux et Niestlé, 1996.

CARREIRA, M. H. Semântica e Discurso, estudos de Linguística Portuguesa e Comparativa (Português/Francês). Porto: Porto, 2001.

CHARAUDEAU, P. Discurso Político. Săo Paulo: Contexto, 2013.

DUARTE, I. Formas de tratamento: item gramatical no ensino do Português Língua Materna.In: A. BRITO. Gramática: história, teorias, aplicaçóes. Porto: Fundaçāo Universidade do Porto - Faculdade de Letras, 2010. Disponível em: <http://ler.letras. up.pt/uploads/ficheiros/8312.pdf>. Acesso em: 15 maio 2014.

DUCROT, O. Le dire et le dit. Paris: Minuit, 1984.

GOFFMAN, E. Les rites d"interaction. Paris: Minuit, 1974.

KERBRAT-ORECCHIONI, C. Système linguistique et ethos communicatif. Cahiers de Praxématique 38, pp. 35-57, 2002. Disponível em: <https://praxematique.revues. org/540>. Acesso em: 10 dez. 2014.

MAINGUENEAU, D. Cenas de Enunciaçăo. Curitiba: Criar, 2006.

PERELMAN, C. 0 império retórico: retórica e argumentaçăo. Porto: Ediçôes ASA, 1993.

RASTIER, F. Arts et Sciences du Texte. Paris: PUF, 2001.

WALTON, D., REED, C., MACAGNO, F. Argumentation Schemes. Cambridge: Cambridge University Press, 2008. 